\title{
STUDI PENYELENGGARAAN PELAYANAN KESEHATAN LINGKUNGAN DI PUSKESMAS KOTA DENPASAR TAHUN 2020
}

\author{
Ni Luh Putu Adelia Irmayanti ${ }^{1}$, Anysiah Elly Yulianti
}

\begin{abstract}
For the implementation of environmental health services in the Public health center need to be analyzed human resources, funding sources, implementation activities, and infrastructure facilities. The purpose of this research is to determine the implementation of environmental health services. Research is conducted throughout the public health center of Denpasar City, by providing an overview, description and analysis of the implementation of environmental health services. The results showed human resources showed a $100 \%$ good figure, all respondents of $100 \%$ expressed the importance of funding sources, as many as 5 public health centers carry out environmental health services every day, and the remaining 6 public health centers carry out according to the schedule. Facilities and infrastructures at the Public health center of Denpasar City there are still less like environmental health laboratories, environmental quality gauges and tool repair tools. Thus it is advised that the public health center that facilities and infrastructure is still lacking to be equipped and to the Public health center that carries out the activities of environmental health services on a schedule/not daily to review to the implementation of environmental health services.
\end{abstract}

Keywords: Services; environmental health; public health center

\section{PENDAHULUAN}

Pelayanan kesehatan lingkungan merupakan wahana masyarakat untuk mengatasi masalah kesehatan lingkungan dan masalah penyakit berbasis lingkungan dengan bimbingan, penyuluhan, dan bantuan teknis dari petugas pelayanan kesehatan lingkungan Puskesmas. Pelayanan kesehatan lingkungan juga merupakan kegiatan wawancara mendalam dan penyuluhan yang bertujuan untuk mengenal masalah lebih rinci, kemudian diupayakan dan dilakukan oleh petugas pelayanan kesehatan lingkungan sehubungan dengan komunikasi penderita/pasien yang dating ke Puskesmas (1)

Ruang lingkup kegiatan pelayanan kesehatan lingkungan Puskesmas mencakup berbagai upaya, antara lain: penyediaan/penyehatan air bersih dan 
sanitasi dalam rangka

pencegahan/penanggulangan penyakit diare/cacingan/kulit/kusta/frambusia, penyehatan perumahan dalam rangka pencegahan penyakit ISPA/TB Paru, Penyehatan lingkungan pemukiman dalam rangka pencegahan penyakit demam berdarah dengue (DHF)/malaria/filariasis, Penyehatan lingkungan tempat kerja dalam rangka pencegahan dan penanggulangan penyakit yang berhubungan dengan lingkungan/akibat kerja, Penyehatan makanan/minuman dalam rangka pencegahan dan penanggulangan penyakit saluran pencernaan/keracunan, Pengamanan pestisida dalam rangka pencegahan dan penanggulangan keracunan pestisida, dan penyakit atau gangguan kesehatan lainnya yang berhubungan dengan lingkungan (2)

Tiga penyakit berbasis lingkungan di Kota Denpasar terdapat penyakit Diare (6.667), Demam Berdarah Dengue (1.307), dan TBC Paru (790).Kota Denpasar memiliki 11 sarana Puskesmas. Di masingmasing Puskesmas sudah ada pelayanan kesehatan lingkungan untuk membantu masyarakat yang ingin melakukan konsultasi tentang masalah penyakit ataupun hal-hal yang berbasis lingkungan (3)
Berdasarkan hasil survei awal yang peneliti lakukan, masih terdapat pelayanan kesehatan lingkungan yang tidak aktif di Puskesmas Kota Denpasar, karena tidak adanya pasien/klien yang mengalami penyakit berbasis lingkungan dirujuk ke pelayanan kesehatan lingkungan dan petugas pelayanan kesehatan lingkungan lebih banyak melakukan kegiatan di lapangan (luar gedung puskesmas).

Tujuan dari penelitian ini adalah untuk mengetahui penyelenggaraan pelayanan kesehatan lingkungan di Puskesmas Kota Denpasar, Adapun tujuan khusus dari penelitian ini adalah: (1) Untuk mengetahui Sumber Daya Manusia dalam penyelenggaraan pelayanan kesehatan lingkungan. (2) Untuk mengetahui sarana dan prasarana dalam penyelenggaraan pelayanan kesehatan lingkungan . (3) Untuk mengetahui sumber dana dalam penyelenggaraan pelayanan kesehatan lingkungan. (4) Untuk mengetahui kegiatan pelayanan kesehatan lingkungan di Puskesmas Kota Denpasar.

Pelayanan Kesehatan Lingkungan adalah kegiatan atau serangkaian kegiatan yang ditunjukan untuk mewujudkan kualitas lingkungan yang sehat baik dari aspek fisik, 
kimia, biologi, maupun social guna mencegah penyakit dan/atau gangguan kesehatan yang diakibatkan oleh faktor risiko lingkungan. (Permenkes, 2015)

Tenaga kesehatan berwenang untuk menyelenggarakan pelayanan kesehatan, kewenangan untuk menyelenggarakan pelayanan kesehatan dilakukan sesuai dengan bidang keahlian yang dimiliki, dalam menyelenggarakan pelayanan kesehatan, tenaga kesehatan wajib memiliki izin dari pemerintah, selama memberikan pelayanan kesehatan dilarang mengutamakan kepentingan yang bernilai materi. Tenaga kesehatan harus memenuhi ketentuan kode etik, standar profesi, hak pengguna pelayanan kesehatan, standar pelayanan dan standar operasional (UU RI No.36, 2014)(4)

Sarana dan prasarana pelayanan kesehatan lingkungan di Puskesmas meliputi ruang untuk konseling yang terintegrasi dengan layanan konseling lain, laboratorium kesehatan lingkungan yang terintegrasi dengan laboratorium yang ada Puskesmas. (Permenkes, 2015)(5).

Adapun sumber dana untuk program klinik sanitasi yang sekarang ini berasal dari dana operasional puskesmas APBN dan APBD Provinsi, APBD Kabupaten/Kota, kemitraan dan swadaya masyarakat setempat 


\section{METODE PENELITIAN}

Jenis penelitian yang digunakan adalah penelitian observasional menggunakan design "cross sectional" yaitu variabel sebab dan akibat atau yang terjadi pada objek penelitian diukur dalam waktu yang bersamaan (6)

Unit analisis dalam penelitian ini adalah penyelenggaraan pelayanan kesehatan lingkungan dengan menganalisis kegiatan pelaksanaan, sumber daya manusia, sarana dan prasarana, sumber dana, Cara yang digunakan untuk mengumpulkan data dalam penelitian ini adalah wawancara, dan observasi.Wawancara yang ditujukan kepada responden dengan panduan kuisoner

\section{HASIL DAN PEMBAHASAN}

\section{Sumber Daya Manusia Di Puskesmas Kota Denpasar}

Sumber Daya Manusia atau tenaga kesehatan di puskesmas berperan sebagai pelaksana pelayanan kesehatan, dalam peran tersebut diharapkan agar tugas pokok dan fungsi (tupoksi) tenaga kesehatan sesuai dengan pendidikan dan ketrampilan yang dimiliki.(7).
Penelitian ini bertujuan untuk memberikan gambaran, deskripsi dan analisis penyelenggaraan pelayanan kesehatan lingkungan dengan melakukan wawancara, dan observasi di pelayanan kesehatan lingkungan Puskesmas. sedangkan responden dan populasi dalam penelitian ini adalah tenaga kesehatan lingkungan di 11 Puskesmas Kota Denpasar yaitu 11 orang yang menjadi jumlah sampel subyek.

yang telah disiapkan, dan observasi yang dilakukan melalui pengamatan langsung di lapangan dengan melihat ruang pelayanan kesehatan lingkungan terkait sarana dan prasarana dengan panduan checklist.

Tenaga pelayanan kesehatan lingkungan di 11 Puskesmas yang ada di Kota Denpasar mempunyai kualitas Sumber Daya Manusia yang sudah baik sehingga menunjukkan angka 100\%.karena sudah mengetahui ruang lingkup, tugas dan fungsi pelayanan kesehatan lingkungan di Puskesmas, kemampuannya dalam melaksanakan penyelenggaraan pelayanan kesehatan lingkungan baik dalam 
wawancara konseling kepada pasien/klien, menyimpulkan permasalahan atau prilaku yang berkaitan dengan penyakit pasien, maupun memberikan saran tindak lanjut sesuai permasalahan yang dihadapi pasien. Seperti pada tabel 1:

Tabel 1

Distribusi Sumber Daya Manusia di Puskesmas Kota Denpasar

\begin{tabular}{|c|c|c|c|}
\hline No & $\begin{array}{c}\text { Sumber Daya } \\
\text { Manusia }\end{array}$ & Jumlah & Presentase \\
\hline 1 & Baik & 11 & 100 \\
\hline 2 & Tidak Baik & 0 & 0 \\
\hline & Total & $\mathbf{1 1}$ & $\mathbf{1 0 0}$ \\
\hline
\end{tabular}

\section{Sarana dan Prasarana di Puskesmas Kota Denpasar}

Setelah melakukan observasi di ruang pelayanan kesehatan lingkungan Puskesmas Kota Denpasar dapat diketahui sudah seluruh Puskesmas tersedia ruang untuk konseling sebanyak $100 \%$, tidak tersedia laboratorium kesehatan lingkungan 100\%, dan sebanyak $54.5 \%$ Puskesmas tersedia alat pengukur kualitas air, sebanyak 100\% Puskesmas tersedia formulir pencatatan kegiatan dan media KIE, untuk ketersediaan cetakan sarana air bersih, alat perbaikan sarana hanya dua puskesmas sebanyak $18.2 \%$, dapat dilihat pada tabel 2 :
Tabel 2

Distribusi Sarana Prasarana di Ruang

Pelayanan Kesehatan Lingkungan Puskesmas Kota Denpasar

\begin{tabular}{|c|c|c|c|}
\hline No & $\begin{array}{c}\text { Sarana } \\
\text { Prasarana }\end{array}$ & Jumlah & Presentase \\
\hline \multirow[t]{4}{*}{1} & \multicolumn{3}{|c|}{ Ruang Konseling } \\
\hline & Tersedia & 11 & 100 \\
\hline & $\begin{array}{l}\text { Tidak } \\
\text { Tersedia }\end{array}$ & 0 & 0 \\
\hline & Total & 11 & 100 \\
\hline \multirow[t]{4}{*}{2} & \multicolumn{3}{|c|}{ Laboratorium Kesehatan Lingkungan } \\
\hline & Tersedia & 0 & 0 \\
\hline & $\begin{array}{l}\text { Tidak } \\
\text { Tersedia }\end{array}$ & 11 & 100 \\
\hline & Total & 11 & 100 \\
\hline \multirow[t]{4}{*}{3} & \multicolumn{3}{|c|}{$\begin{array}{l}\text { Alat Pengukur Kualitas Lingkungan } \\
\text { (Air) }\end{array}$} \\
\hline & Tersedia & 6 & 54.5 \\
\hline & $\begin{array}{l}\text { Tidak } \\
\text { Tersedia }\end{array}$ & 5 & 45.5 \\
\hline & Total & 11 & 100 \\
\hline \multirow[t]{4}{*}{4} & \multicolumn{3}{|c|}{$\begin{array}{l}\text { Media Komunikasi Informasi } \\
\text { Edukasi (Leaflet, Poster, dll) }\end{array}$} \\
\hline & Tersedia & 11 & 100 \\
\hline & $\begin{array}{l}\text { Tidak } \\
\text { Tersedia }\end{array}$ & 0 & 0 \\
\hline & Total & 11 & 100 \\
\hline \multirow[t]{4}{*}{5} & \multicolumn{3}{|c|}{ Formulir Pencatatan Kegiatan } \\
\hline & Tersedia & 11 & 100 \\
\hline & $\begin{array}{l}\text { Tidak } \\
\text { Tersedia }\end{array}$ & 0 & 0 \\
\hline & Total & 11 & 100 \\
\hline \multirow[t]{4}{*}{6} & \multicolumn{3}{|c|}{$\begin{array}{l}\text { Cetakan sarana air besih, alat } \\
\text { perbaikan sarana }\end{array}$} \\
\hline & Tersedia & 2 & 18.2 \\
\hline & $\begin{array}{l}\text { Tidak } \\
\text { Tersedia }\end{array}$ & 9 & 81.8 \\
\hline & Total & 11 & 100 \\
\hline
\end{tabular}


Dalam upaya pencapaian tujuan kebijakan harus didukung dengan ketersediaan sarana dan prasarana, tanpa sarana dan prasarana yang memadai tugas pekerjaan spesifik tidak dapat diselesaikan sebagaimana seharusnya, pekerjaan tidak mungkin dapat dilakukan bahkan akan mengalami hambatan ketersediaan sarana dan prasarana merupakan faktor penentu kebijakan. Pelaksana harus mendapat sumber yang dibutuhkan agar program berjalan.(8)

\section{Sumber Dana di Puskesmas Kota Denpasar}

Sebanyak 100\% Puskesmas Kota Denpasar mengatakan sumber dana sangat berpengaruh terhadap kegiatan pelaksanaan pelayanan kesehatan lingkungan. Dapat dilihat seperti pada tabel 3 :

Tabel 3

Distribusi Sumber Dana di Puskesmas Kota Denpasar

\begin{tabular}{|c|c|c|c|}
\hline No & Sumber Dana & Jumlah & Presentase \\
\hline 1 & Berpengaruh & 11 & 100 \\
\hline 2 & $\begin{array}{c}\text { Tidak } \\
\text { berpengaruh }\end{array}$ & 0 & 0 \\
\hline & Total & $\mathbf{1 1}$ & $\mathbf{1 0 0}$ \\
\hline
\end{tabular}

Sumber dana di Puskesmas berasal dari APBD (Anggaran Pendapatan Belanja Daerah) dan BOK (Bantuan Operasional Kesehatan). BOK adalah Bantuan dana dari Pemerintah melalui Kementerian Kesehatan dalam membantu Pemerintahan Kabupaten/Kota melaksanakan pelayanan kesehatan sesuai Standar Palayanan Minimal (SPM) Bidang Kesehatan menuju Millenium Development Goals (MDGs) dengan meningkatkan kinerja Puskesmas dan jaringannya serta Poskesdes dan Posyandu dalam menyelenggarakan pelayanan kesehatan promotif dan preventif. (9)

\section{Pelaksanaan Pelayanan Kesehatan Lingkungan di Puskesmas Kota Denpasar}

Setelah melakukan penelitian di 11 Puskesmas yang ada di Kota Denpasar, pelaksanaan pelayanan kesehatan lingkungan sudah semua berjalan dengan angka $100 \%$, seperti pada tabel 4 :

Tabel 10

Distribusi Pelaksanaan Pelayanan

Kesehatan Lingkungan di Puskesmas Kota Denpasar

\begin{tabular}{|c|c|c|c|}
\hline No & $\begin{array}{c}\text { Pelaksanaan } \\
\text { Pelayanan Kesehatan } \\
\text { Lingkungan }\end{array}$ & Jumlah & Presentase \\
\hline 1 & Berjalan & 11 & 100 \\
2 & Tidak Berjalan & 0 & 0 \\
\hline & Total & $\mathbf{1 1}$ & $\mathbf{1 0 0}$ \\
\hline
\end{tabular}

Penyelenggaraan pelayanan kesehatan lingkungan di Puskesmas Kota Denpasar sudah semua berjalan, akan tetapi hanya lima Puskesmas memberikan pelayanannya setiap hari, selebihnya dilaksanakan secara 
terjadwal baik dua kali dalam seminggu, dan ada Puskesmas yang melaksanakan hanya seminggu sekali. Konseling merupakan bagian terpenting untuk mengenali lebih awal penyakit berbasis lingkungan yang dialami pasien. Hasil konseling diakhiri dengan memberikan solusi dan penentuan tindak lanjut berupa home care atau inspeksi kunjungan rumah(10).Demi terselenggaranya pelayanan kesehatan lingkungan di Puskesmas penting jika dilaksanakan setiap hari kerja untuk mengatasi penyakit berbasis lingkungan yang dialami pasien atau klien yang ingin berkonsultasi tentang masalah kesehatan lingkungan.

\section{SIMPULAN DAN SARAN}

Berdasarkan hasil penelitian
penyelenggaraan pelayanan kesehatan
lingkungan di Puskesmas Kota Denpasar
dapat disimpulkan sebagai berikut : (1)
Kualitas SDM pelayanan kesehatan
lingkungan Puskesmas Kota Denpasar sudah
100\% baik. (2) Sarana dan Prasarana di
pelayanan kesehatan lingkungan Kota
Denpasar masih ada yang kurang seperti
laboratorium kesehatan lingkungan, alat
pengukur kualitas lingkungan (air), dan

cetakan sarana air besih, alat perbaikan sarana. (3) Sebanyak 100\% responden mengatakan bahwa sumber dana sangat berpengaruh untuk menunjang sarana dan prasarana. (4) Penyelenggaraan pelayanan kesehatan lingkungan di Puskesmas Kota Denpasar sudah $100 \%$ berjalan, baik dilaksanakan setiap hari kerja ataupun secara terjadwal.

Saran-saran yang penulis sampaikan: (1) Penyelenggaraan pelayanan kesehatan lingkungan di Puskesmas Kota Denpasar masih ada yang melaksanakan tidak setiap hari kerja dan secara terjadwal seminggu sekali. Untuk itu diharapkan melaksanakan pelayanan minimal dua kali dalam seminggu agar bisa memberikan pelayanan kepada seluruh pasien/klien yang mengalami permasalahan terkait dengan penyakit berbasis lingkungan. (2) Diharapkan kepada pihak pengelola Puskesmas Kota Denpasar untuk melengkapi sarana dan prasarana yang masih kurang guna memperlancar kegiatan penyelenggaraan pelayanan kesehatan lingkungan, sehingga dapat memberikan pelayanan yang maksimal. 


\section{DAFTAR PUSTAKA}

1. Putri AM, Mulasari SA. Klinik Sanitasi Dan Perannya Dalam Peningkatan Kesehatan Lingkungan Di Puskesmas Pajangan Bantul. J Ilm Kesehat. 2018;

2. Depkes. Pedoman Pelaksanaan Klinik Sanitasi Untuk Puskesmas. In Jakarta: Depatermen Kesehatan RI Ditjen PPM \& PL; 2003.

3. Dinkes. Laporan Tahunan Hasil Pelaksanaan Kegiatan Program. In Denpasar: Dinas Kesehatan Kota Denpasar; 2018.

4. RI U. Undang-Undang RI, 2014 No. 36 Tentang Tenaga Kesehatan. 2014;

5. Permenkes RI. Peraturan Menteri Kesehatan RI, 2015. No 13. Penyelenggaraan Pelayanan Kesehatan Lingkungan di Puskesmas. Jakarta. 2015;
6. Notoatmodjo S. Metode Penelitian Kesehatan. Jakarta: PT Rineka Cipta; 2012. 37 p.

7. Handayani L, Sopacua E. Peran Tenaga Kesehatan Sebagai Pelaksana Pelayanan Kesehatan Puskesmas. J Kesehat. 2010;

8. Rahayu T. Evaluasi Pelaksanaan Program Pencegahab Dan Penanggulangan Penyakit Demam Berdarah Dengue Di Wilayah Kerja Puskesmas Ketapang 2. 2012;

9. Dasmar, Darmawansyah, Jafar N. Studi Evaluasi Program Dana Bantuan Operasional Kesehatan Di Kabupaten Luwu. J AKK. 2013;

10. Sugiharto M, Oktami RS. Pelaksanaan Klinik Sanitasi Di Puskesmas Gambut Dalam Menaggulangi Penyakit Berbasis Lingkungan. 2018; 